\title{
Structural identification of mouse fecal metabolites of theaflavin 3,3'-digallate using liquid chromatography tandem mass spectrometry
}

\author{
Huadong Chen ${ }^{a}$, Tiffany A. Parks ${ }^{a}$, Xiaoxin Chen ${ }^{b}$, Nicholas D. Gillitt ${ }^{c}$, Christian Jobin ${ }^{d}$, and \\ Shengmin Sang ${ }^{\mathrm{a},}{ }^{*}$ \\ a Center for Excellence in Post-Harvest Technologies, North Carolina Agricultural and Technical \\ State University, North Carolina Research Campus, 500 Laureate Way, Kannapolis, NC 28081, \\ USA \\ ${ }^{b}$ Cancer Research Program, Julius L. Chambers Biomedical/Biotechnology Research Institute, \\ North Carolina Central University, 700 George Street, Durham, NC 27707, USA \\ c Dole Nutrition Research Laboratory, North Carolina Research Campus, 600 Laureate Way, \\ Kannapolis, NC 28081, USA \\ d Department of Medicine, Pharmacology and Immunology/Microbiology and the Center for \\ Gastrointestinal Biology and Disease, University of North Carolina at Chapel Hill, Chapel Hill, NC \\ 27599, USA
}

\begin{abstract}
Black tea consumption has been associated with many health benefits including the prevention of cancer and heart disease. Theaflavins are the major bioactive polyphenols present in black tea. Unfortunately, limited information is available on their biotransformation. In the present study, we investigated the metabolic fate of theaflavin $3,3^{\prime}$-digallate (TFDG), one of the most abundant and bioactive theaflavins, in mouse fecal samples using liquid chromatography/electrospray ionization tandem mass spectrometry by analyzing the $\mathrm{MS}^{n}(n=1-3)$ spectra. Four metabolites theaflavin, theaflavin 3-gallate, theaflavin $3^{\prime}$-gallate, and gallic acid were identified as the major mouse fecal metabolites of TFDG. Glucuronidated and sulfated, instead of methylated metabolites of theaflavin 3-gallate, theaflavin 3 '-gallate, and TFDG were detected and identified as the minor mouse fecal metabolites of TFDG. Our results indicate that TFDG can be degraded in mice. Further studies on the formation of those metabolites in TFDG-treated mice in germ-free conditions are warranted. To our knowledge, this is the first report on the biotransformation of TFDG in mice.
\end{abstract}

\section{Keywords}

Theaflavin 3,3'-digallate; Mice; Metabolites; Liquid chromatography-tandem mass; spectrometry

\section{Introduction}

As a popular beverage, tea (Camellia sinensis, Theaceae) has been associated with many beneficial health effects, including the prevention of cancer and heart disease [1-3], a phenomenon mostly attributed to the presence of polyphenolic compounds. There are three

\footnotetext{
(C) 2011 Elsevier B.V. All rights reserved.

*Corresponding author. Tel.: +1 704250 5710; fax: +1 704250 5709. ssang @ ncat.edu (S. Sang)..
} 
principal types of tea, namely green (unfermented), oolong (partially fermented) and black (fully fermented) tea, the latter representing $\sim 78 \%$ of worldwide tea production. The main polyphenols in black tea are theaflavins and thearubigins, which are formed by the oxidation and polymerization of catechins in tea leaves during fermentation. Theaflavins including theaflavin (TF), theaflavin-3-gallate (TF3G), theaflavin- $3^{\prime}$-gallate (TF3 $\left.{ }^{\prime} \mathrm{G}\right)$, and theaflavin-3, $3^{\prime}$-digallate (TFDG) (Fig. 1), possess a benzotropolone skeleton that is formed from co-oxidation of selected pairs of catechins. Thearubigins, which have higher molecular weights, are poorly characterized chemically. In black tea, catechins, theaflavins and thearubigins account for $3-10 \%, 2-6 \%$, and greater than $20 \%$, respectively, of the waterextractable material by dry weight [4-6].

Recently, theaflavins have received extensive attention due to their antioxidative, antiinflammatory, and anti-tumor activities [7,8]. Theaflavins have been shown to scavenge hydroxyl radicals with TFDG being the most active component [9] and to inhibit lipid oxidation detected in the rabbit erythrocyte ghost system [10] and in rat liver homogenates [11]. Studies have demonstrated that TFDG blocks nitric oxide synthase by down-regulating the activation of NF- $\mathrm{kB}$ and suppresses lipopolysaccharide-induced NF- $\kappa \mathrm{B}$ activity through down-regulation of I $\kappa B$ kinase activity in macrophages [12,13]. Theaflavins $(0.1 \%$ in drinking fluid) significantly reduced tumor multiplicity and volume by $23 \%$ and $34 \%$, respectively, in 4-(methylnitrosamino)-1-(3-pyridyl)-1-butanone-induced lung tumorigenesis in A/J mice [14]. Oral administration of TFDG $(5 \mathrm{mg} / \mathrm{kg}$ daily i.g.) significantly improved trinitrobenzene sulfonic acid (TNBS)-induced colitis in mice and inhibited production of inflammatory mediators through a mechanism that involves inhibition of NF- $\kappa \mathrm{B}$ activation [15]. The C3(1)/SV40 T-antigen transgenic mice treated with theaflavins (0.05\% in drinking fluid) survived longer and had smaller breast tumors as compared to control mice [16].

It has been reported, however, that theaflavins have poor systematic bioavailability. Mulder et al. reported that the Cmax of theaflavin in human plasma and urine was only $1 \mathrm{ng} / \mathrm{mL}$ and $4.2 \mathrm{ng} / \mathrm{mL}$, respectively, following consumption of $700 \mathrm{mg}$ of a pure mixture of theaflavins, which is equivalent to about 30 cups of black tea [17]. Neither theaflavin mono- nor digallates were detectable in this study. Very limited amounts of TFDG $(<1 \mathrm{nmol} / \mathrm{g}$ tissue $)$ were detected in tissue samples collected from mice treated with decaffeinated black tea ( 50 $\mathrm{mg} / \mathrm{g}$ diet) for two weeks [18]. Therefore, it is puzzling how theaflavins, especially TFDG, can exert their biological protective functions despite such low bioavailability. Studies have shown that higher molecular weight polyphenols are metabolized by the microbiota and that their metabolites may play an important role in their health benefits [19-21]. Clearly, a comprehensive understanding of TFDG metabolism is essential to understanding the health benefits conferred by this compound as well as black tea. To our knowledge, there is no report on the biotransformation of theaflavins. In recent years, liquid chromatography/ tandem mass spectrometry (LC/MS/MS) has evolved as a valuable tool for structural analysis of the metabolites of many bioactive polyphenols. In the present study, we analyzed the metabolic profile of TFDG from mouse feces using liquid chromatography/electrospray ionization (ESI) tandem mass spectrometry. The structures of eight major metabolites were identified by analyzing the $\mathrm{MS}^{2}$ and $\mathrm{MS}^{3}$ spectra of each compound.

\section{Experimental}

\subsection{Materials}

TF, TF3G, TF3' G, and TFDG were prepared previously in our laboratory [22]. Gallic acid was purchased from Sigma-Aldrich (St. Louis, MO, USA). LC/MS-grade solvents and other reagents were obtained from Fisher Scientific (Pittsburgh, PA, USA). 


\subsection{Treatment of mice and feces collection}

Experiments with mice were carried out according to a protocol approved by the Institutional Review Board for the Animal Care and Facilities Committee at North Carolina Central University. Female C57BL/6J mice were purchased from the Jackson Laboratory (Bar Harbor, ME, USA) and allowed to acclimate for at least 1 week prior to the start of the experiment. The mice were housed 5 per cage and maintained in air-conditioned quarters with a room temperature of $20 \pm 2{ }^{\circ} \mathrm{C}$, relative humidity of $50 \pm 10 \%$, and an alternating 12h light/dark cycle. Mice were fed Purina Rodent Chow \#5001 (Research Diets) and water, and were allowed to eat and drink ad libitum. TFDG in dimethyl sulfoxide (DMSO) was administered to mice by oral gavage $(200 \mathrm{mg} / \mathrm{kg})$. Feces and urine samples were collected in metabolism cages ( 5 mice per cage) for $24 \mathrm{~h}$ after administration of vehicle (control group, $n$ $=5$ ) or TFDG (treated group, $n=5$ ). These samples were stored at $-80{ }^{\circ} \mathrm{C}$ before analysis.

\subsection{Fecal and urine sample preparation}

For the metabolic profile, four pieces of each fecal sample (control and treated) were chosen and put into $2 \mathrm{~mL}$ tubes. Each set was weighed (control: $75.0 \mathrm{mg}$ and treated: $77.0 \mathrm{mg}$ ) and $1.0 \mathrm{~mL}$ of $50 / 50 \mathrm{MeOH} /$ water $+0.1 \%$ formic acid was added to each sample. Samples were sonicated for $90 \mathrm{~min}$ then vortexed to mix well, then centrifuged at $17(\times 1000) \mathrm{rpm}$ for 10 min. $650 \mu \mathrm{L}$ of the supernatants were removed from the centrifuged samples and transferred to LC/MS vials for analysis. In order to determine whether TFDG is stable under these conditions, TFDG in 50/50 MeOH/water $+0.1 \%$ formic acid $(10 \mu \mathrm{M})$ was sonicated for 90 min and then transferred to LC/MS vials for analysis. The urine samples $(50 \mu \mathrm{L}$ from each group, control group and TFDG-treated group) were added to $200 \mu \mathrm{L}$ methanol to precipitate proteins. After centrifugation at $17(\times 1000) \mathrm{rpm}$ for $5 \mathrm{~min}$, the supernatant was transferred into vials for LC/MS analysis.

\subsection{HPLC analysis}

An HPLC-ECD (ESA, Chelmsford, MA) consisting of an ESA model 584 HPLC pump, an ESA model 542 autosampler, an ESA organizer, and an ESA coularray detector coupled with two ESA model 6210 four sensor cells was used in our study. A Gemini C18 column (150 mm $\times 4.6 \mathrm{~mm}, 5 \mu \mathrm{m}$; Phenomenex, Torrance, CA, USA) was used for chromatographic analysis at a flow rate of $1.0 \mathrm{~mL} / \mathrm{min}$. The mobile phases consisted of solvent A (30 mM sodium phosphate buffer containing $1.75 \%$ acetonitrile and $0.125 \%$ tetrahydrofuran, $\mathrm{pH} 3.35)$ and solvent $\mathrm{B}(15 \mathrm{mM}$ sodium phosphate buffer containing $58.5 \%$ acetonitrile and $12.5 \%$ tetrahydrofuran, $\mathrm{pH} 3.45$ ). The gradient elution had the following profile: 0\% B from 0 to $10 \mathrm{~min}$; 0-30\% B from 10 to $20 \mathrm{~min}$; 30-40\% B from 20 to $35 \mathrm{~min}$; $40-50 \%$ B from 35 to $50 \mathrm{~min}$; 50-100\% B from 50 to $55 \mathrm{~min}$; $100 \%$ B from 55 to $59 \mathrm{~min}$; and then $0 \% \mathrm{~B}$ from 59.1 to $65 \mathrm{~min}$. The cells were then cleaned at a potential of $1000 \mathrm{mV}$ for $1 \mathrm{~min}$. The injection volume of the sample was $10 \mu \mathrm{L}$.

\subsection{LC/ESI-MS method}

LC/MS analysis was carried out with a Thermo-Finnigan Spectra System which consisted of an Accela high-speed MS pump, an Accela refrigerated autosampler, and an LTQ Velos ion trap mass detector (Thermo Electron, San Jose, CA, USA) incorporated with heated electrospray ionization (H-ESI) interfaces. A Gemini C18 column $(50 \mathrm{~mm} \times 2.0 \mathrm{~mm}$ i.d., 3 $\mu \mathrm{m}$; Phenomenex, Torrance, CA, USA) was used for separation of theaflavins and their potential phase II metabolites at a flow rate of $0.2 \mathrm{~mL} / \mathrm{min}$. The column was eluted with $100 \%$ solvent $\mathrm{A}\left(\mathrm{H}_{2} \mathrm{O}\right.$ with $0.1 \%$ formic acid) for $3 \mathrm{~min}$, followed by linear increases in B (acetonitrile with $0.1 \%$ formic acid) to $70 \%$ from 3 to $48 \mathrm{~min}$ and to $100 \%$ B from 48 to 49 $\mathrm{min}$, and then with $100 \% \mathrm{~B}$ from 49 to $54 \mathrm{~min}$. The column was re-equilibrated with $100 \%$ A for $5 \mathrm{~min}$. A Kinetex C18 column $(100 \mathrm{~mm} \times 4.6 \mathrm{~mm}$ i.d., $5 \mu \mathrm{m}$; Phenomenex, Torrance, 
CA, USA) was used for separation of phenolic acids and their potential phase II metabolites at a flow rate of $0.4 \mathrm{~mL} / \mathrm{min}$. The column was eluted with $100 \%$ solvent $\mathrm{A}\left(\mathrm{H}_{2} \mathrm{O}\right.$ with $0.1 \%$ formic acid) for $3 \mathrm{~min}$, followed by linear increases in B (acetonitrile with $0.1 \%$ formic acid) to $70 \%$ from 3 to $23 \mathrm{~min}$ and to $100 \%$ from 23 to $24 \mathrm{~min}$, and then with $100 \%$ B from 24 to $29 \mathrm{~min}$. The column was re-equilibrated with $100 \%$ A for $5 \mathrm{~min}$. The LC eluent was introduced into the H-ESI interface. The negative ion polarity mode was set for the H-ESI source with the voltage on the H-ESI interface maintained at approximately $4 \mathrm{kV}$. Nitrogen gas was used as the sheath gas and auxiliary gas. To detect the theaflavins and their phase II metabolites, optimized source parameters, including ESI capillary temperature $\left(300{ }^{\circ} \mathrm{C}\right)$, capillary voltage $(-50 \mathrm{~V})$, ion spray voltage $(3.6 \mathrm{kV})$, sheath gas flow rate (30 units), auxiliary gas flow rate (5 units), and tube lens $(-120 \mathrm{~V})$, were tuned using authentic TFDG. To detect the phenolic acids and their phase II metabolites, optimized source parameters were tuned using authentic gallic acid. These parameters include ESI capillary temperature $\left(300{ }^{\circ} \mathrm{C}\right)$, capillary voltage $(50 \mathrm{~V})$, ion spray voltage $(3.6 \mathrm{kV})$, sheath gas flow rate $(35$ units),-auxiliary gas flow rate (15 units), and tube lens $(-60 \mathrm{~V})$. The collision-induced dissociation (CID) for H-ESI was conducted with an isolation width of $2 \mathrm{Da}$ and normalized collision energy of 35 for $\mathrm{MS}^{2}$ and $\mathrm{MS}^{3}$. Default automated gain control target ion values were used for MS, $\mathrm{MS}^{2}$, and $\mathrm{MS}^{3}$ analyses. The mass range was from 50 to $1500 \mathrm{~m} / \mathrm{z}$. The mass resolution was 0.6 amu FWHM. Data acquisition was performed with Xcalibur version 2.1.0 (Thermo Electron, San Jose, CA, USA).

\section{Results and discussion}

The strategy that we used for structural characterization of TFDG metabolites was knowledge-based metabolic identification. Simple phenols and phenolic acids have been reported as the microbial-derived degradation products of higher molecular weight polyphenols [19-21]. In this study, we searched the existence of potential microbial-derived metabolites of TFDG including TF, TF3G, TF3'G, GA, diHBA, pyrogallol, 3,4dihydroxyphenylpropionic acid (diHPP), 3,4-dihydroxyphenylacetic acid (diHPAc), $m$ hydroxyphenylacetic acid ( $m$-HPAc), phenylacetic acid (PAc), vanillic acid (VA), $m$ hydroxybenzoic acid ( $m \mathrm{HBA}$ ), $p$-hydroxybenzoic acid ( $p$-HBA), hippuric acid (HA), $m$ coumaric acid (m-CA), 4-hydroxyphenyl acetic acid (4-HPAc), 3-methoxy-4-hydroxyphenyl acetic acid (homo-VA), 5-( $3^{\prime}, 4^{\prime}, 5^{\prime}$-trihydroxyphenyl)- $\gamma$-valerolactone (M4), 5-( $3^{\prime}, 4^{\prime}$ dihydroxyphenyl)- $\gamma$-valerolactone (M6), and their related phase II metabolites.

In addition, glucuronidation, sulfation, and methylation represent the major metabolic pathways for tea catechins [23]. We predict that TFDG may also be a substrate for glucuronidation, sulfation, and methylation. Therefore, we also searched the phase II metabolites of TFDG including TFDG glucuronide ( $\mathrm{m} / \mathrm{z} 1044)$, TFDG sulfate $(\mathrm{m} / \mathrm{z} 948)$, mono-methylated TFDG $(\mathrm{m} / \mathrm{z} 882)$, di-methylated TFDG $(\mathrm{m} / \mathrm{z} 896)$, mono-methylated TFDG monoglucuronide $(\mathrm{m} / \mathrm{z} 1058)$, mono-methylated TFDG mono-sulfate $(\mathrm{m} / \mathrm{z} 962)$, TFDG mono-glucuronide and mono-sulfate $(\mathrm{m} / \mathrm{z} 1124)$, and mono-methylated TFDG monoglucuronide and mono-sulfate $(\mathrm{m} / \mathrm{z} 1138)$.

The fecal and urine samples collected both from control mice and mice treated with $200 \mathrm{mg}$ / kg TFDG via oral gavage were analyzed by HPLC coupled with electrochemical detector (ECD) (Fig. 2) as well as negative ESI-MS (Figs. 3-8). Among all the possible metabolites that we searched, TF, TF3G, TF3' G, and GA were identified as the major metabolites of TFDG and glucuronidated and sulfated metabolites as the minor metabolites in mouse fecal samples (Table 1). None of those metabolites were detected from the TFDG positive control sample indicating that TFDG is stable under the conditions that were used to prepare mouse fecal samples. We could not detect any metabolites in urine samples from mice treated with TFDG (data not shown). 


\subsection{Identification of gallic acid as metabolite of TFDG}

In the HPLC-ECD chromatograms, there was one peak in the fecal samples collected from TFDG-treated mice had an almost identical retention time as that of authentic gallic acid (Fig. 2C and E). Further LC/MS analysis confirmed that this peak was gallic acid (Fig. 3A). There was one peak shown in the fecal samples collected from TFDG-treated mice under the selected ion monitoring (SIM) mode of $\mathrm{m} / \mathrm{z} 169[\mathrm{M}-\mathrm{H}]^{-}$(molecular ion of gallic acid under negative mode). This peak had an almost identical retention time and $\mathrm{MS}^{2}$ spectrum as authentic gallic acid (Fig. 3A). Therefore, metabolite M1 was identified as gallic acid (Fig. 1).

\subsection{Identification of TF, TF3G and TF3'G as metabolites of TFDG}

In the extracted chromatogram of $\mathrm{m} / \mathrm{z} 563[\mathrm{M}-\mathrm{H}]^{-}$(molecular ion of TF under ESI negative mode), one new peak (M2) was found in the fecal samples collected from TFDG treated mice (Fig. 3B). Peak M2 (RT: $22.71 \mathrm{~min}$ ) had a molecular weight of 564 as determined by the mass ions at $\mathrm{m} / z 563[\mathrm{M}-\mathrm{H}]^{-}$and $1127[2 \mathrm{M}-\mathrm{H}]^{-}$, which is the same as that of TF $(\mathrm{m} / \mathrm{z}$ 564) (spectra were not shown). Then we compared the retention time and the tandem mass spectrum of peak M2 with those of authentic TF. Our results indicated that they had almost identical retention times and mass fragments (Fig. 3B). Therefore, peak M2 is identified as TF (Fig. 1), which lost two gallate groups from TFDG.

In the extracted chromatogram of $\mathrm{m} / \mathrm{z} 715[\mathrm{M}-\mathrm{H}]^{-}$(molecular ion of TF3G and TF3 ${ }^{\prime} \mathrm{G}$ under ESI negative mode), two new peaks (M3 and M4) were found in the fecal samples collected from TFDG treated mice (Fig. 4). Peaks M3 and M4 both had a molecular weight of $m / z 716$ as determined by the mass ion at $m / z 715[\mathrm{M}-\mathrm{H}]^{-}$. Their retention times and MS/ MS spectra were almost identical to those of authentic TF3G and TF3' $\mathrm{G}$ (Fig. 4), indicating that peaks M3 and M4 are TF3G and TF3' G, respectively, each of which lost one of the two gallate groups from TFDG (Fig. 1).

In addition, in the extracted chromatogram of $\mathrm{m} / z 867[\mathrm{M}-\mathrm{H}]^{-}$(molecular ion of TFDG under ESI negative mode), one peak was found in the fecal samples collected from TFDG treated mice (Fig. 3C). This peak had an almost identical retention time and $\mathrm{MS}^{2}$ spectrum as those of authentic TFDG (Fig. 3C) indicating that there was unmetabolized TFDG in mouse fecal samples.

Studies have shown that theaflavins, especially TFDG, have poor systematic bioavailability. TFDG was not detected in human plasma and urine following consumption of $700 \mathrm{mg}$ of a pure mixture of theaflavins [17] and only trace amounts of TFDG $(<1 \mathrm{nmol} / \mathrm{g}$ tissue $)$ were detected in tissue samples collected from mice treated with decaffeinated black tea $(50 \mathrm{mg} / \mathrm{g}$ diet) for two weeks [18]. However, in vivo studies have shown that theaflavins have antiinflammatory and anti-tumor activities $[7,14,15]$. Studies have also shown that microbialderived metabolites of higher molecular weight polyphenols may play an important role in their health benefits 19-21]. Therefore, it is possible that the degradation products of TFDG observed in this study are responsible for the reported beneficial effects of TFDG. Gallic acid has indeed been reported to have anti-inflammatory and anti-tumor activities [24-29]. However, the impact of this metabolite on the anti-inflammatory and cancer preventive effects of theaflavins needs to be further studied, especially under in vivo conditions. In addition, the interplay between microorganisms and theaflavins is a topic for future study.

\subsection{Identification of glucuronidated and sulfated metabolites of TFDG}

In the extracted chromatogram of $\mathrm{m} / \mathrm{z} 1034[\mathrm{M}-\mathrm{H}]^{-}$(molecular ion of mono-glucuronidated TFDG under negative mode), seven major peaks (M5-1-M5-7) were observed from fecal samples collected from TFDG-treated mice. They all had similar tandem mass spectra with 
$\mathrm{m} / \mathrm{z} 867$ (molecular ion of TFDG under negative mode) as the major product ion indicating that they are potential mono-glucruonidated metabolites of TFDG (Fig. 5). In order to further confirm that those compounds were the metabolites of TFDG, we compared the MS ${ }^{3}$ spectra of the product ion $\mathrm{m} / \mathrm{Z} 867$ of those seven compounds with the MS ${ }^{2}$ spectrum of authentic TFDG (Figs. 3c and 5B-H). Our results clearly indicated that the $\mathrm{MS}^{3}$ spectra of the product ion $\mathrm{m} / \mathrm{z} 867$ were almost identical to the $\mathrm{MS}^{2}$ spectrum of authentic TFDG suggesting that all the seven compounds were the mono-glucuronidated metabolites of TFDG (Fig. 1). There are 13 hydroxyl groups in the structure of TFDG, in which 11 potential mono-glucuronidated metabolites of TFDG can be formed in theory. Since the active sites of TFDG for gulcuronition have not been identified, we cannot provide the structures of metabolites M5-1-M5-7.

Similarly, in the extracted chromatogram of $\mathrm{m} / \mathrm{z} 867[\mathrm{M}-\mathrm{H}]^{-}$taken from the $\mathrm{MS}^{2}$ data set obtained from $\mathrm{m} / \mathrm{z} 947[\mathrm{M}-\mathrm{H}]^{-}$(molecular ion of mono-sulfated TFDG under negative mode), five peaks (M6-1-M6-5) were observed from the TFDG-treated mouse fecal samples. This suggested that they were potential mono-sulfated metabolites of TFDG (Fig. 6). The $\mathrm{MS}^{3}$ spectra of the product ion $\mathrm{m} / \mathrm{z} 867$ of those five compounds (Fig. 6B-F) and the $\mathrm{MS}^{2}$ spectrum of TFDG standard (Fig. 3C) showed the same fragment ion mass spectra indicating that all of those five peaks were the mono-sulfated metabolites of TFDG. At this stage, we cannot provide the structures of those metabolites.

\subsection{Identification of glucuronidated and sulfated metabolites of TF3G and TF3'G}

Our results indicated that TFDG was a substrate for glucuronidation and sulfation. We predicted that TF, TF3G and TF3' $\mathrm{G}$ were also substrates for glucuronidation and sulfation. In the extracted chromatogram of $\mathrm{m} / \mathrm{z} 715[\mathrm{M}-\mathrm{H}]^{-}$(molecular ion of TF3G and TF3 ${ }^{\prime} \mathrm{G}$ under negative mode) taken from the $\mathrm{MS}^{2}$ data set obtained from $\mathrm{m} / z 891[\mathrm{M}-\mathrm{H}]^{-}$ (molecular ion of mono-glucuronidated $\mathrm{TF} 3 \mathrm{G}$ or $\mathrm{TF}^{\prime} \mathrm{G}$ under negative mode). Five peaks (M7-1-M7-5) were observed from the TFDG-treated mouse fecal samples. This indicated that they were potential mono-glucruonidated metabolites of TF3G or TF3' G (Fig. 7). Then, we compared the $\mathrm{MS}^{3}$ spectra of the product ion $\mathrm{m} / \mathrm{z} 715$ of those five compounds with the $\mathrm{MS}^{2}$ spectrum of authentic TF3G or TF3'G (Figs. 4 and 7). Our results shown that all of those compounds had the same fragment ion mass spectra as the authentic TF3G or TF3 ${ }^{\prime} \mathrm{G}$. From the structure of $\mathrm{TF} 3 \mathrm{G}$ or $\mathrm{TF}^{\prime} \mathrm{G}$, nine potential glucuronidated metabolites can be formed in theory. We cannot provide the exact structures of metabolites M7-1-M7-5. Similarly, in the extracted chromatogram of $\mathrm{m} / \mathrm{z} 715[\mathrm{M}-\mathrm{H}]^{-}$taken from the $\mathrm{MS}^{2}$ data set obtained from $\mathrm{m} / \mathrm{z} 795[\mathrm{M}-\mathrm{H}]^{-}$(molecular ion of mono-sulfated TF3G or TF3' $\mathrm{G}$ under negative mode), three peaks (M8-1-M8-3) were observed from the TFDG-treated mouse fecal samples (Fig. 8A). The MS $\mathrm{M}^{3}$ spectra of the product ion $\mathrm{m} / \mathrm{z}$ present study four major metabolites were detected in fecal samples collected from mice treated with TFDG. Their structures were determined using tandem mass spectrometry as well as by comparing with authentic standards. This is the first report on the biotransformation of TFDG. Our results indicated that (1) TFDG is extensively metabolized in mice; (2) the major metabolites of TFDG are TF, TF3G, TF3 ' $\mathrm{G}$, and GA, which are most likely generated by gut microflora; and (3) glucuronidation and sulfation but not methylation are the minor biotrasformation pathway of TFDG. On the basis of metabolites identified in this study, the major metabolic pathways of TFDG are proposed in Fig. 1.

\section{Abbreviations}

$\begin{array}{ll}\text { TF } & \text { theaflavin } \\ \text { TF3G } & \text { theaflavin 3-gallate }\end{array}$




$\begin{array}{ll}\text { TF3 }^{\prime} \mathbf{G} & \text { theaflavin } 3^{\prime} \text {-gallate } \\ \text { TFDG } & \text { theaflavin } 3,3^{\prime} \text {-digallate } \\ \text { diHBA } & \text { 3,4-dihydroxybenzoic acid } \\ \text { GA } & \text { gallic acid } \\ \text { LC/MS } & \text { iquid chromatrography/mass spectrometry }\end{array}$

\section{References}

1. Chacko SM, Thambi PT, Kuttan R, Nishigaki I. Chin. Med. 2010; 5:13. [PubMed: 20370896]

2. Yang CS, Wang X, Lu G, Picinich SC. Nat. Rev. Cancer. 2009; 9:429. [PubMed: 19472429]

3. Higdon JV, Frei B. Crit. Rev. Food Sci. Nutr. 2003; 43:89. [PubMed: 12587987]

4. Balentine DA, Wiseman SA, Bouwens LC. Crit. Rev. Food Sci. Nutr. 1997; 37:693. [PubMed: 9447270]

5. Yang CS, Ju J, Lu G, Xiao H, Hao X, Sang S, Lambert JD. Asia Pac. J. Clin. Nutr. 2008; 17(Suppl. 1):245. [PubMed: 18296347]

6. Haslam E. Phytochemistry. 2003; 64:61. [PubMed: 12946406]

7. Kumar G, Pillare SP, Maru GB. Mini Rev. Med. Chem. 2010; 10:492. [PubMed: 20370700]

8. Sharma V, Rao LJ. Crit. Rev. Food Sci. Nutr. 2009; 49:379. [PubMed: 19399668]

9. Yang Z, Jie G, Dong F, Xu Y, Watanabe N, Tu Y. Toxicol. In Vitro. 2008; 22:1250. [PubMed: 18502093]

10. Shiraki M, Hara Y, Osawa T, Kumon H, Nakayama T, Kawakishi S. Mutat. Res. 1994; 323:29. [PubMed: 7508563]

11. Yoshino K, Hara Y, Sano M, Tomita I. Biol. Pharm. Bull. 1994; 17:146. [PubMed: 8148805]

12. Lin YL, Tsai SH, Lin-Shiau SY, Ho CT, Lin JK. Eur. J. Pharmacol. 1999; 367:379. [PubMed: 10079014]

13. Pan MH, Lin-Shiau SY, Ho CT, Lin JH, Lin JK. Biochem. Pharmacol. 2000; 59:357. [PubMed: 10644043]

14. Yang GY, Liu Z, Seril DN, Liao J, Ding W, Kim S, Bondoc F, Yang CS. Carcinogenesis. 1997; 18:2361. [PubMed: 9450482]

15. Ukil A, Maity S, Das PK. Br. J. Pharmacol. 2006; 149:121. [PubMed: 16880762]

16. Kaur S, Greaves P, Cooke DN, Edwards R, Steward WP, Gescher AJ, Marczylo TH, Agric J. Food Chem. 2007; 55:3378.

17. Mulder TP, van Platerink CJ, Wijnand Schuyl PJ, van Amelsvoort JM. J. Chromatogr. B: Biomed. Sci. Appl. 2001; 760:271. [PubMed: 11530986]

18. Henning SM, Aronson W, Niu Y, Conde F, Lee NH, Seeram NP, Lee RP, Lu J, Harris DM, Moro A, Hong J, Pak-Shan L, Barnard RJ, Ziaee HG, Csathy G, Go VL, Wang H, Heber D. J. Nutr. 2006; 136:1839. [PubMed: 16772446]

19. Forester SC, Waterhouse AL. J. Nutr. 2009; 139:1824S. [PubMed: 19640966]

20. Larrosa M, Luceri C, Vivoli E, Pagliuca C, Lodovici M, Moneti G, Dolara P. Mol. Nutr. Food Res. 2009; 53:1044. [PubMed: 19557820]

21. Rios LY, Gonthier MP, Remesy C, Mila I, Lapierre C, Lazarus SA, Williamson G, Scalbert A. Am. J. Clin. Nutr. 2003; 77:912. [PubMed: 12663291]

22. Sang S, Lambert JD, Tian S, Hong J, Hou Z, Ryu JH, Stark RE, Rosen RT, Huang MT, Yang CS, Ho CT. Bioorg. Med. Chem. 2004; 12:459. [PubMed: 14723964]

23. Sang S, Lambert JD, Ho CT, Yang CS. Pharmacol. Res. 2011

24. Kroes BH, van den Berg AJ, Quarles van Ufford HC, van Dijk H, Labadie RP. Planta Med. 1992; 58:499. [PubMed: 1336604]

25. Ji BC, Hsu WH, Yang JS, Hsia TC, Lu CC, Chiang JH, Yang JL, Lin CH, Lin JJ, Suen LJ, Gibson Wood W, Chung JG. J. Agric. Food Chem. 2009; 57:7596. [PubMed: 20349925] 
26. Raina K, Rajamanickam S, Deep G, Singh M, Agarwal R, Agarwal C. Mol. Cancer Ther. 2008; 7:1258. [PubMed: 18445658]

27. Min SW, Ryu SN, Kim DH. Int. Immunopharmacol. 2010

28. Mori H, Matsunaga K, Tanakamaru Y, Kawabata K, Yamada Y, Sugie S, Nishikawa A. Cancer Lett. 1999; 135:123. [PubMed: 10096419]

29. Lin HH, Chen JH, Chou FP, Wang CJ. Br. J. Pharmacol. 2011; 162:237. [PubMed: 20840540] 


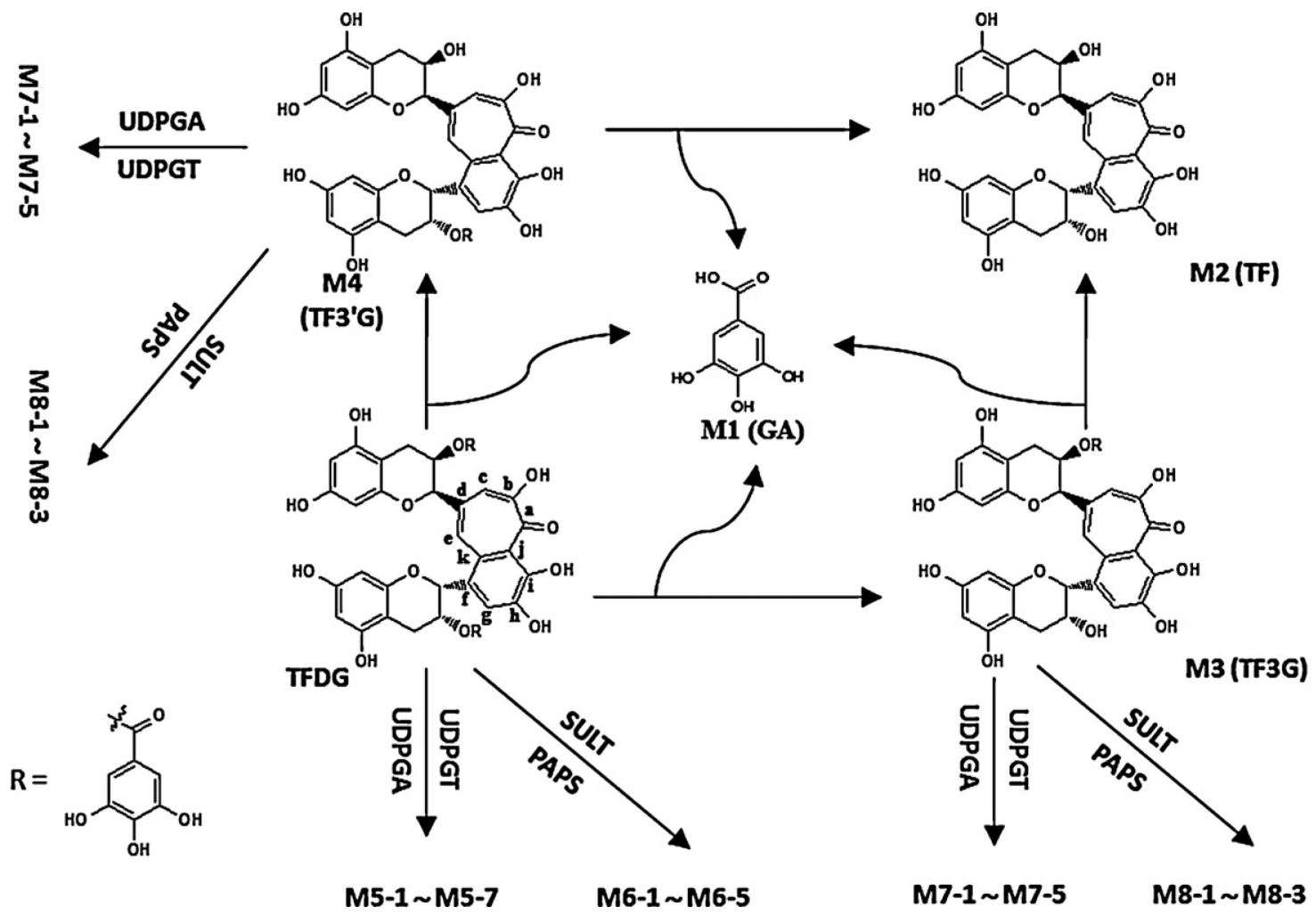

Fig. 1.

Structures of TFDG and its major metabolites and possible biotransformation pathways of TFDG. TFDG: theaflavin 3,3'-digallate; TF3G: theaflavin 3-gallate; TF3' G: theaflavin $3{ }^{\prime}$ gallate; TF: theaflavin; GA: gallic acid. 


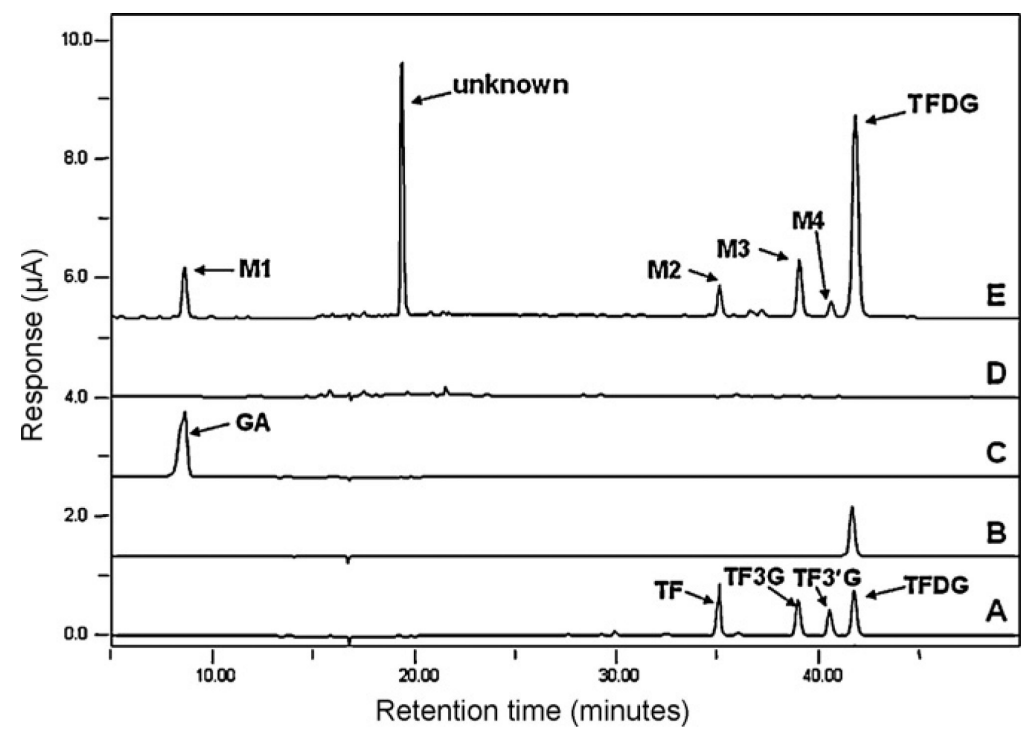

Fig. 2.

HPLC-ECD chromatograms of a mixture of authentic theaflavin (TF), theaflavin 3-gallate (TF3G), theaflavin $3^{\prime}$-gallate $\left(\mathrm{TF} 3^{\prime} \mathrm{G}\right)$ and theaflavin $3,3^{\prime}$-digallate $(\mathrm{A})$; authentic theaflavin $3,3^{\prime}$-digallate (TFDG) administrated to mice via oral gavage (B); authentic gallic acid (GA) (C); fecal samples collected from control mice (D); and fecal samples collected from TFDG treated mice $(\mathrm{E})$. 

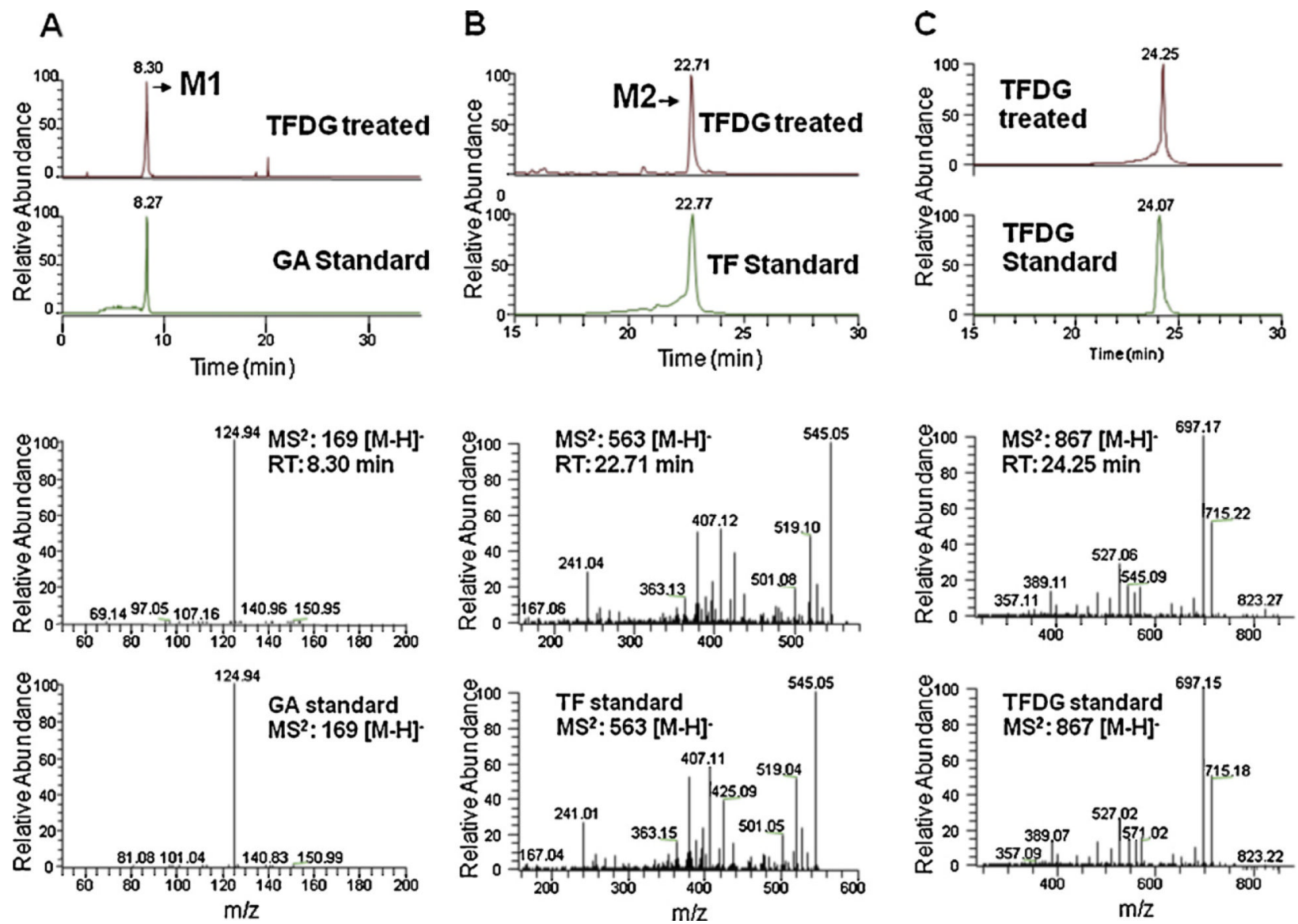

Fig. 3.

(A) LC chromatograms of fecal samples collected from TFDG treated mice as well as authentic gallic acid (GA) obtained by negative ESI/MS interface extracted with $\mathrm{m} / z 169$ $[\mathrm{M}-\mathrm{H}]^{-} ; \mathrm{MS} / \mathrm{MS}$ (negative ion) spectra of the major metabolite (M1) corresponding to $\mathrm{m} / \mathrm{z}$ $169[\mathrm{M}-\mathrm{H}]^{-}$in fecal samples collected from TFDG treated mice and authentic GA; (B) LC chromatograms of fecal samples collected from TFDG treated mice as well as authentic TF obtained by negative ESI/MS interface extracted with $\mathrm{m} / z 563[\mathrm{M}-\mathrm{H}]^{-}$; MS/MS (negative ion) spectra of the major metabolite (M2) corresponding to $\mathrm{m} / \mathrm{z} 563[\mathrm{M}-\mathrm{H}]^{-}$in fecal samples collected from TFDG treated mice and authentic TF; and (C) LC chromatograms of fecal samples collected from TFDG treated mice as well as authentic TFDG obtained by negative ESI/MS interface extracted with $\mathrm{m} / z 867[\mathrm{M}-\mathrm{H}]^{-}$; MS/MS (negative ion) spectra of the peak corresponding to $m / z 867[\mathrm{M}-\mathrm{H}]^{-}$in fecal samples collected from TFDG treated mice and authentic TFDG. 



Fig. 4.

(A) LC chromatograms of fecal samples collected from control mice and TFDG treated mice as well as a mixture of authentic TF3D and TF3' D obtained by negative ESI/MS interface extracted with $\mathrm{m} / \mathrm{z} 715$ [M-H $^{-}$; (B) MS/MS (negative ion) spectra of the two major metabolites (M3-M4) corresponding to $\mathrm{m} / z 715[\mathrm{M}-\mathrm{H}]^{-}$in fecal samples collected from TFDG treated mice; and (C) MS/MS (negative ion) spectra of authentic TF3G and TF3' G. 

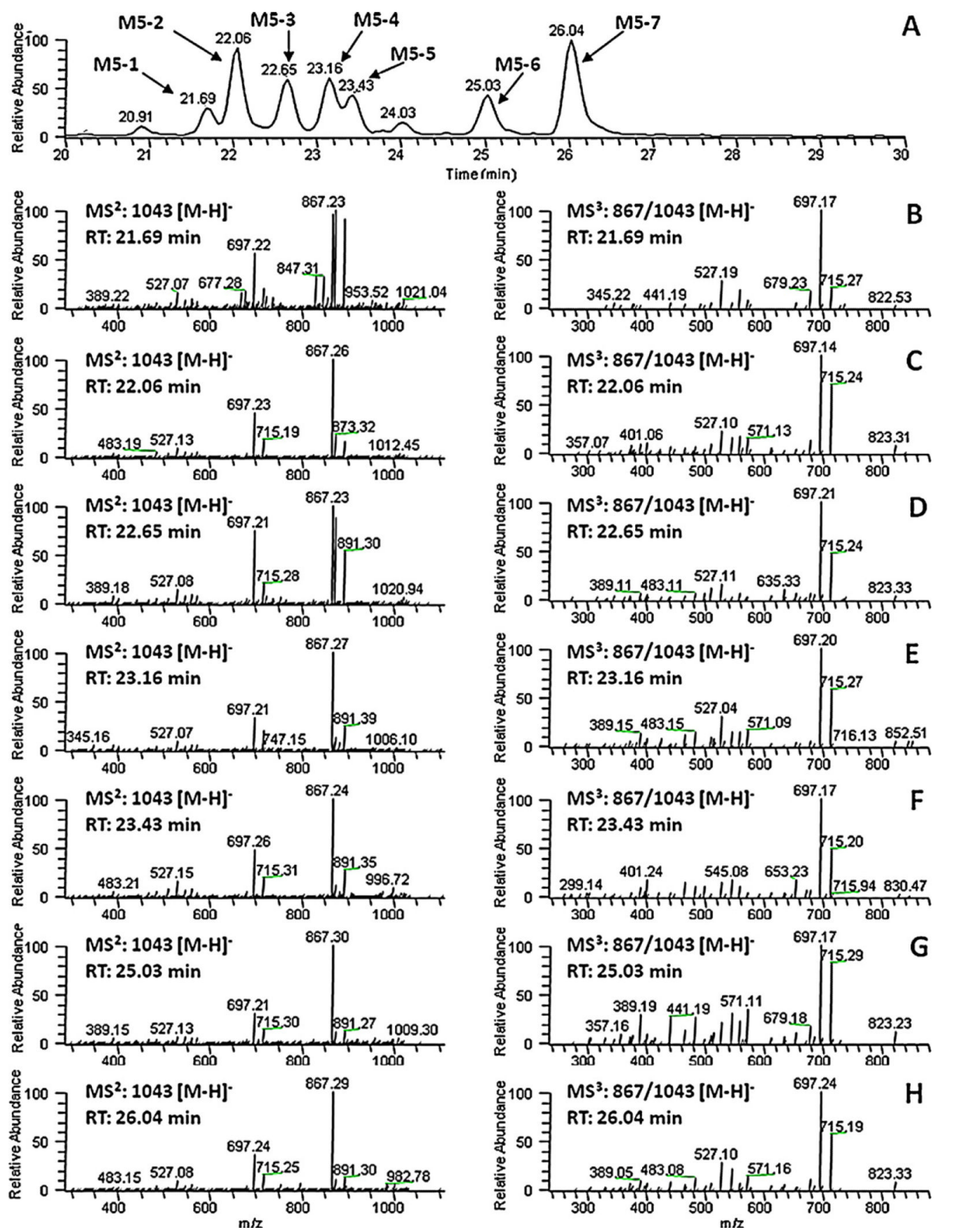

Fig. 5.

(A) LC chromatograms of fecal samples collected from TFDG treated mice obtained by negative ESI/MS interface extracted with $\mathrm{m} / z 1043[\mathrm{M}-\mathrm{H}]^{-}$; and $(\mathrm{B}-\mathrm{H}) \mathrm{MS} / \mathrm{MS}$ (negative ion) spectra of the seven major metabolites (M5-1-M5-7) corresponding to $\mathrm{m} / \mathrm{z} 1043$ [M$\mathrm{H}]^{-}$and $\mathrm{MS}^{3}$ spectra of these metabolites corresponding to $\mathrm{m} / \mathrm{z} 867 / 1043[\mathrm{M}-\mathrm{H}]^{-}$in fecal samples collected from TFDG treated mice. 


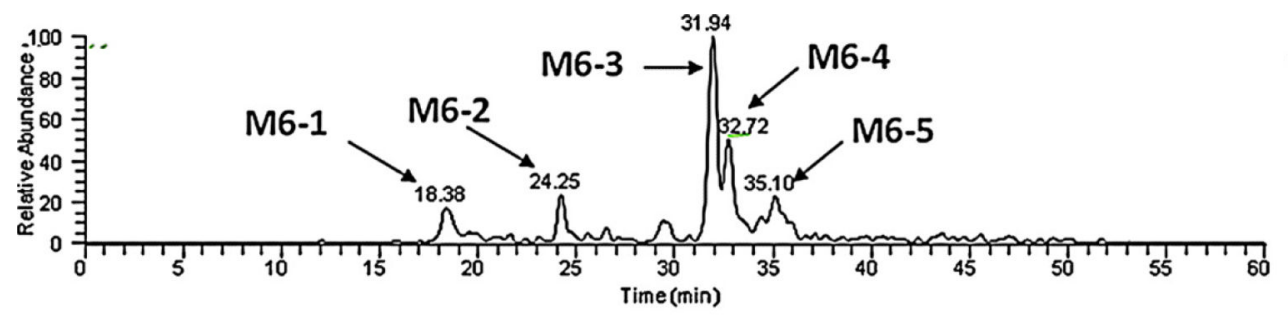

A


Fig. 6.

(A) LC chromatograms of fecal samples collected from TFDG treated mice obtained by negative ESI/MS interface extracted with $\mathrm{m} / \mathrm{z} 947$ [M-H] ${ }^{-}$; and (B-F) MS/MS (negative ion) spectra of the seven major metabolites (M6-1-M6-5) corresponding to $\mathrm{m} / \mathrm{z} 947$ [M-H] ${ }^{-}$ and $\mathrm{MS}^{3}$ spectra of these metabolites corresponding to $\mathrm{m} / \mathrm{z}$ 867/947 [M-H] $]^{-}$in fecal samples collected from TFDG treated mice. 

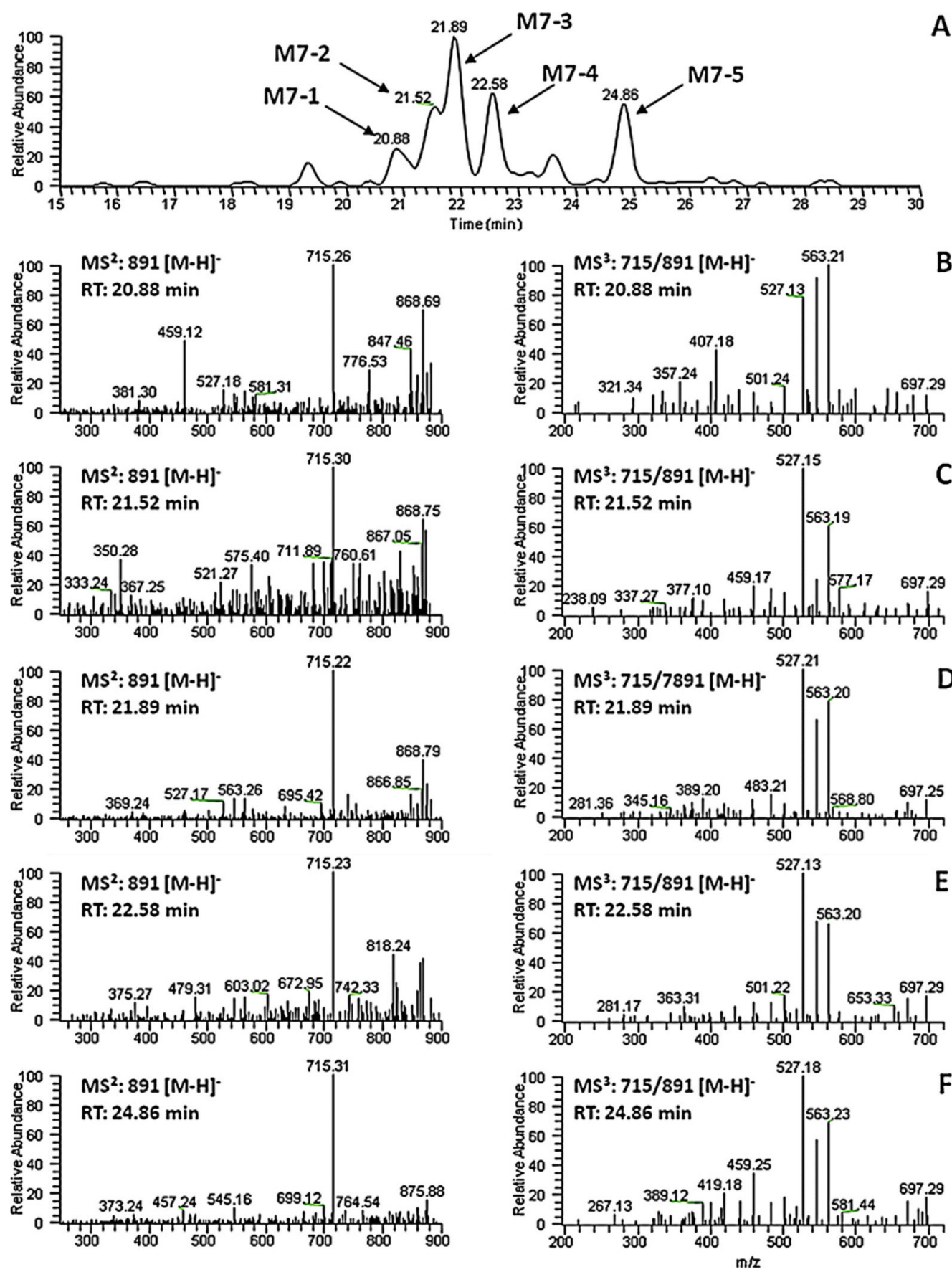

Fig. 7.

(A) LC chromatograms of fecal samples collected from TFDG treated mice obtained by negative ESI/MS interface extracted with $\mathrm{m} / \mathrm{z} 891[\mathrm{M}-\mathrm{H}]^{-}$; and (B-F) MS/MS (negative ion) spectra of the five major metabolites (M7-1-M7-5) corresponding to $\mathrm{m} / z$ 891 [M-H] ${ }^{-}$ and $\mathrm{MS}^{3}$ spectra of these metabolites corresponding to $\mathrm{m} / \mathrm{z} 715 / 891[\mathrm{M}-\mathrm{H}]^{-}$in fecal samples collected from TFDG treated mice. 

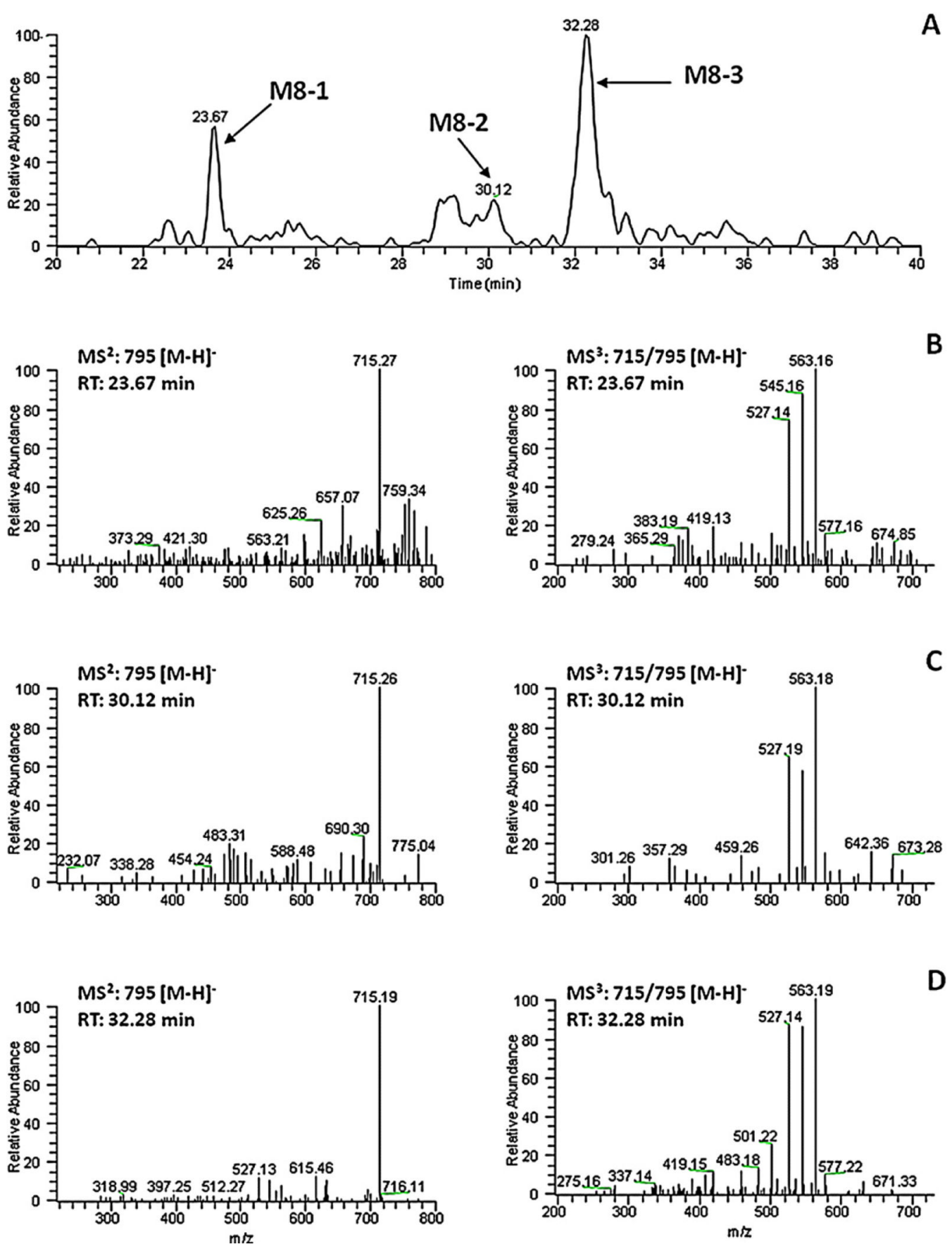

Fig. 8.

(A) LC chromatograms of fecal samples collected from TFDG treated mice obtained by negative ESI/MS interface extracted with $\mathrm{m} / \mathrm{z} 795[\mathrm{M}-\mathrm{H}]^{-}$; and (B-D) MS/MS (negative ion) spectra of the three major metabolites (M8-1-M8-3) corresponding to $\mathrm{m} / \mathrm{z} 795[\mathrm{M}-\mathrm{H}]^{-}$ and $\mathrm{MS}^{3}$ spectra of these metabolites corresponding to $\mathrm{m} / \mathrm{z} 715 / 795[\mathrm{M}-\mathrm{H}]^{-}$in fecal samples collected from TFDG treated mice. 
Table 1

Major mouse fecal metabolites of TFDG.

\begin{tabular}{|c|c|c|c|c|}
\hline Name & Peak number & RT (min) & Molecular weight & MS/MS fragments (relative intensity, \%) \\
\hline GA & M1 & 8.30 & 170 & $125(100)$ \\
\hline $\mathrm{TF}$ & $\mathrm{M} 2$ & 22.71 & 564 & $545(100), 519(47), 425(34), 407(57), 379(47)$ \\
\hline TF3G & M3 & 23.49 & 716 & 697 (18), 577 (26), $563(87), 545$ (76), 527 (100) \\
\hline $\mathrm{TF}^{\prime} \mathrm{G}$ & M4 & 23.92 & 716 & $697(28), 577(31), 563(100), 545(68), 527(33), 407(56)$ \\
\hline \multirow[t]{7}{*}{ Glu-TFDG } & M5-1 & 21.69 & 1044 & $697(60), 867(100), 891(89)$ \\
\hline & M5-2 & 22.06 & 1044 & $697(50), 867(100), 891(21)$ \\
\hline & M5-3 & 22.65 & 1044 & $697(76), 867(100), 891(56)$ \\
\hline & M5-4 & 23.16 & 1044 & $697(35), 867(100), 891(24)$ \\
\hline & M5-5 & 23.43 & 1044 & $697(52), 867(100), 891(28)$ \\
\hline & M5-6 & 25.03 & 1044 & $697(36), 867(100), 891(15)$ \\
\hline & M5-7 & 26.04 & 1044 & $697(36), 867(100), 891(14)$ \\
\hline \multirow[t]{5}{*}{ Sul-TFDG } & M6-1 & 18.38 & 948 & $867(100)$ \\
\hline & M6-2 & 24.25 & 948 & $867(100)$ \\
\hline & M6-3 & 31.94 & 948 & $867(100)$ \\
\hline & M6-4 & 32.72 & 948 & $867(100)$ \\
\hline & M6-5 & 35.10 & 948 & $867(100)$ \\
\hline \multirow[t]{5}{*}{ Glu-TF3G or Glu-TF3' G } & M7-1 & 20.88 & 892 & $715(100)$ \\
\hline & M7-2 & 21.52 & 892 & $715(100)$ \\
\hline & M7-3 & 21.89 & 892 & $715(100)$ \\
\hline & M7-4 & 22.58 & 892 & $715(100)$ \\
\hline & M7-5 & 24.86 & 892 & $715(100)$ \\
\hline \multirow[t]{3}{*}{ Sul-TF3G or Sul-TF3' G } & M8-1 & 23.67 & 796 & $715(100)$ \\
\hline & M8-2 & 30.12 & 796 & $715(100)$ \\
\hline & M8-3 & 32.28 & 796 & $715(100)$ \\
\hline
\end{tabular}

